\title{
Integrated Pest Management: A Grower's Perspective
}

\author{
Dan Tawczynski \\ Taft Farms, Inc., 21 Division Street, Great Barrington, MA 01230
}

Taft Farms is an 80-ha mixed-vegetable farm growing primarily for retail sales. From a business point of view, we buy products we don't raise and contract other growers to produce items according to our distinct growing philosophy. (We use organic methods as far as they go and use commercial nutrients to pick up the slack and keep things in balance. Pesticides are used only as a last resort to save a crop.) An example of this is raspberries. We purchase the entire crop of another grower as long as he follows our methodology. We agree on a price beforehand, and I supply him with all necessary support and materials.

We have a highly diverse operation-perhaps too diverse. Life would be a lot simpler if we could narrow it down and focus on a few crops, but in a sense our unusual approach has trapped us. Our customers are demanding even greater diversity. We raise a number of crops for "pick your own." Response is tremendous, and we find that customers tend to buy more than they would ordinarily.

When we started out as growers in the 1950s, we used few pesticides, largely because we didn't know about their availability. As time went on, we used as many chemicals as anyone in the business.

Cost factors were originally the reason for our minimizing pesticides. As resistance grew, it didn't take a rocket scientist to figure out that something was wrong. We stopped spraying by the calendar, started a meaningful rotation schedule, and started to monitor pest activity a lot more closely.

We found ourselves getting more and more involved with understanding the nature of the beast and minimizing the conditions that were favorable to it. With this approach we were able to virtually eliminate most fungicide and insecticide sprays by 1980 . Eventually, some guidelines were established to determine whether a control measure had to be employed. Again, I emphasize that these guidelines were based solely on economics. Environmental concerns had not yet hit home, and pressure from our customers ranged from light to nonexistent.

In the early 1980s, The Univ. of Massachusetts announced the beginning of the Integrated Pest Management program. Soon I found that what we had been doing already was pretty much what they were doing, but they were definitely more sophisticated in the way they did it. The numbers for our "economic thresholds" were virtually the same.

With the resources of the Univ. of Massachusetts and other universities we were able to refine our efforts and eventually eliminate the use of most pesticides without sacrificing yield or quality. I should point out that we are relatively isolated and not easily influenced by someone else's resistance problems. Moving in a nonpesticidal direction was considerably easier for us than it would be for anyone located in a heavily farmed area.

Our focus now is toward keeping pest levels below the point where action has to be taken. We have used many kinds of predators. Especially successful have been several Trichogramma species and predatory yeasts. Most other predators are at sufficient levels to keep their prey in check.

We are now working with nutrition as a means of pest control. I firmly believe that stress from lack of proper nutrition, especially in the minor elements, is a major factor in proper pest management. When we manage nutrients properly and keep stress of any kind to a minimum, pest control is not only much easierbut in many cases not needed at all.

Because we could not find plant foods of the types we needed, we developed our own, tailored to our specific needs. The most common deficiency we encountered was apparently carbon, translating into the plant's inability to make adequate sugar. Lack of sugar seems to be the reason nutritional stress shows up even when the nutrients are apparently present. We have found a chelated form of carbon that seems to address this problem by helping in the sugar formation. I can't say that the carbon is the reason sugar is enhanced, but there definitely is more sugar present after treatment with the carbon than before.

I am not a trained observer, but I do recognize most insects and diseases when I see them, and I see significantly fewer pests in our field now since we are paying closer attention to nutrition than when we simply sprayed something on our problems.

We make compost and spread -20 ha of our farm every year. Autumn leaves, lawn clippings, harvested lake weeds, and chicken manure are the primary ingredients in our compost. On occasion we have spread fresh manure, much to the chagrin of my neighbors.

Now for my crystal ball: All is not well on the horizon. Organically grown produce generally commands a higher price in the marketplace, and it must because the inputs, especially labor, are much higher. (I measure inputs in terms of cost, not whether they are "natural or synthetic.") We all must become more efficient, and to do this we as farmers need your help.

It's time to come down from your ivory towers of academics and gene-splicing and get dirty. We at least need to have balance between basic and applied research. The guys out there in the trenches need a hand with something they can use right now, not 30 years from now. This doesn't mean that basic research should stop, but those who do applied research should not be held back in the academic arena! There is a real need for this research in the public domain.

Take a wild guess who is the largest supplier of organically grown products right now-a wholly owned subsidiary of the Dow Chemical Co. Talk about a contradiction in terms! There is good reason for this. When we, as the "natural" community, told the public that they were being poisoned by the so-called "conventional" agriculture, I don't think even we realized the size of the monster we created. Demand for our products soared, and prices went crazy at the same time. Did we expect the big guys to sit still while people spent large amounts of cash on something other than their product? Did we expect them to simply stop growing and take up transcendental meditation? The big guys respond to one thing very well-money. They just found ways to produce what we grew on a scale we couldn't afford or imagine and for a much lower cost.

Ladies and gentlemen, the handwriting is on the wall. Get efficient at what you do or find something else to do. A basic fact of business is that if you can do something well and can make money at it, others will come along who can do it better, cheaper, faster, or whatever, and soon they will take over your market unless you continually strive to improve your product.

There is a serious problem in that precious little of our research is aimed at improving efficiency of production. This is what I mean by doing more applied research. Not much of this can be done in a lab. Get out to the front lines. You will see farmers, survivors, are tackling the issue. They need a much closer working relationship with academic personnel if we both intend to survive. After all, this is a mutual relationship. 